\title{
Gianpietro Del Piero: a scientist on the edge between engineering sciences and functional analysis
}

Published online: 21 December 2012

(C) Springer-Verlag Berlin Heidelberg 2012

A constant in prof Del Piero's scientific life was the revisitation of the fundamentals and the quest for new, effective mathematical models for Continuum Mechanics. This forced him to repeatedly enlarge his background, to include significant parts of modern mathematics.

Del Piero is a true engineer: he deeply knows the correct "practice" needed to construct in an efficient ways structures and complex engineering devices. In a pretty seminar about the "Domes," (http://www.sdelevicivita. it/2012/11/seminar-by-prof-gianpietro-del-piero-title-domes/) their constructive properties and the history of their construction during the centuries, he managed to show to the audience how the knowledge of the most practical aspects of structural engineering cannot be separated from the mastering of important parts of theoretical mechanics.

Professor Del Piero is one of the first mechanicians who, since the very beginning of their diffusion outside the cultural environment of pure mathematics, understood the impact and importance that measure theory and many aspects of functional analysis may have in continuum mechanics.

His appreciation of the powerful tools supplied by functional analysis began as early as 1974, when he became assistant professor of Variational Methods at the Università di Pisa, in this way starting the construction of the strong mathematical background on which he based his whole scientific activity.

The reader who looks at his list of publications and his CV discovers that he applied sophisticated mathematics to model the mechanical behavior of concrete, brick walls, maintenance and durability of concrete structures, ductile-brittle transition in engineering materials, and many other phenomena in structural mechanics, plasticity, damage propagation, viscoelasticity, cohesion and adhesion.

He also was involved in the conception of experimental measurements and numerical codes developed by younger researchers, always using his theoretical knowledge to choose the appropriate methodologies.

Professor Del Piero has been a paladin of theoretical knowledge as an essential tool in engineering sciences, in a time in which mathematics and any form of theoretical knowledge are being more or less openly disdained.

$\mathrm{He}$ is one of the most skilled contemporary experts of fracture and plasticity. He is well aware of the importance of a careful description of the phenomena. For this, he resorts to the main tool which human mind conceived for problem solving, that is, what Galileo called "the language of mathematics".

Even if he has been sometimes considered as a crypto-mathematician infiltrated among the engineers or, conversely, as an engineer infiltrated in among the mathematicians, what he did was simply to follow his Archimedean point of view: mathematics is a tool which the engineer has to master if he wants to master the

F. dell'Isola $(\varangle)$

Dipartimento di Ingegneria Strutturale e Geotecnica, Sapienza Università di Roma,

Via Eudossiana, 1800198 Rome, Italy

E-mail: francesco.dellisola@uniroma1.it; fdellisola@gmail.com

S. Forest

Centre des Matériaux, MINES Paristech, CNRS UMR 7633,

10 rue Henri Desbruères, BP 87, 91003 Evry Cedex, France

E-mail: samuel.forest@mines-paristech.fr 
real world. This point of view we share with him, and for this reason it was a great pleasure and honor to be called to edit this special issue. We hope that Prof. Del Piero, now free of all kind of obligation, will eventually devote himself exclusively to the activity he likes more: research. 